\title{
Model Kemasan Bentuk Penyajian Musik Dangdut Klasik Pada Grup Musik Rhomantika, Mijen, Semarang
}

\author{
Ummun Nisa Sulistyaningtyas \\ Jurusan Sendratasik, FBS, Universitas Negeri Semarang, Indonesia
}

Suharto ${ }^{\bowtie}$

Jurusan Sendratasik, Fakultas Bahasa dan Seni, Universitas Negeri Semarang, Indonesia

\begin{abstract}
Info Artikel Tujuan penelitian ini adalah untuk mengetahui, menganalisis dan mendeskripsikan model kemasan bentuk penyajian musik dangdut klasik yang ditampilkan oleh kelompok musik dangdut Rhomantika. Metode penelitian yang digunakan dalam

Sejarah Artikel:

Diterima

Disetujui

Dipublikasikan

Kata Kunci

Model Kemasan, Bentuk

Penyajian, Musik

Dangdut Klasik penelitian ini adalah deskriptif kualitatif. Teknik pengumpulan data berupa observasi, angket, wawancara, dan dokumentasi. Hasil penelitian menunjukkan bentuk penyajian pada grup musik Rhomantika termasuk dalam jenis penyajian musik campuran, yaitu penyajian karya musik yang memadukan antara penyajian vocal dan musik instrumental. Model kemasan musik dangdut klasik terdiri dari dua aspek yaitu indoor dan outdoor. Pada model kemasan indoor, dilakukan di dalam ruangan yaitu di studio Rhomantika. Kegiatan yang dilakukan adalah melakukan video shooting bersama seluruh personil dan penyanyi ibukota. Pada model kemasan outdoor, dilakukan di dalam ruangan yaitu di studio Rhomantika. Kegiatan yang dilakukan adalah menampilkan lagu sesuai konsep bersama penyanyi ibukota. Kedua model dilengkapi dengan bentuk penyajian baik tata rias, busana, panggung, lampu, suara sesuai model kemasan baik indoor maupun outdoor.
\end{abstract}

The purpose of this research is to know, analyze and describe the packaging model of classical dangdut presentation form presented by Rhomantika dangdut music group. The research method used in this research is descriptive qualitative. Data collection techniques such as observation, questionnaires, interviews, and documentation. The results showed the form of presentation on the Rhomantika music group included in the type of mixed music presentation, namely the presentation of music that combines both vocal presentation and instrumental music. Classic dangdut music packaging model consists of two aspects: indoor and outdoor. In the indoor packaging model, done indoors is in the studio Rhomantika. Activities performed is to do video shooting with all personnel and singers of the capital. In the outdoor packaging model, done indoors is in the studio Rhomantika. Activities performed is to perform the song in accordance with the concept of singer of the capital. Both models are equipped with a form of presentation of good makeup, fashion, stage, lamp, sound according to both indoor and outdoor packaging models

$\bowtie$ Jurusan Sendratasik, Kampus Sekaran Unnes

ISSN 2301-6744 Gunungpati, Semarang 50229

PENDAHULUAN
Musik dangdut adalah salah satu genre musik di Indonesia yang merupakan perpaduan antara musik melayu dan India. Musik dangdut merupakan musik "rakyat" 
dimana pada genre musik ini terdapat salah satu magnet yang membuat pendengarnya hanyut dan ikut bergoyang seiring diperdengarkannya lagu tersebut. Menurut Dangdut stories : a social and musikal history of Indonesia's most popular musik, karya Weintraub (2005:52), disebutkan bahwa musik dangdut merupakan pengaruh dari musik India dan musik asli Indonesia.

Weintraub (2005:67) menjelaskan unsur-unsur yang terkandung dalam musik dangdut adalah campuran dari musik Melayu, India dan Arab yang membawa musik gambus dan qasidah. Dengan transformasi yang perlahan-lahan, musik dangdut menemukan bentuk sesungguhnya seperti yang didengar sekarang. Dilihat dari irama, nada, dan hentakan kendang yang dimainkan dapat dilihat bahwa musik dangdut mempunyai ciri khas tersendiri jika dibandingkan dengan genre musik yang lain. Jodi Akbar menyatakan (2011:10), musik dangdut berkembang cukup pesat. Dilihat dari bentuk penyajian dan bentuk aransemen musik dangdut yang dimainkan dari masa ke masa terdapat perbedaan. Tujuan pengembangan musik dangdut agar lebih diminati dan digemari oleh khalayak umum. Diantaranya adalah musik dangdut koplo, musik dangdut house, musik dangdut pop dan ada juga yang masih setia dengan musik dangdut klasik atau murni.

Menurut Jodi (2011:78), musik dangdut koplo mulai berkembang pada tahun 2007 dengan munculnya beberapa grup musik dangdut dari Jawa Timur. Grup musik dangdut tersebut menitikberatkan pada ritmis kendang dan break khas pada lagu dangdut yang dimainkan. Berbeda dengan musik dangdut house dan musik dangdut pop yang telah terpengaruh oleh jenis genre musik pop dan musik digital. Banyak masyarakat yang mulai menggemari jenis musik dangdut yang telah dijabarkan tersebut.

Tidak semua grup musik dangdut terpengaruh dan ikut dalam pengembangan jenis musik dangdut baru seperti itu. Salah satunya adalah Grup Musik Rhomantika. Grup Musik tersebut memilih musik dangdut klasik untuk tetap dilestarikan. Grup musik Rhomantika merupakan sebuah kelompok musik yang berada di Jalan Wonolopo Raya, RT 02, RW 07, Mijen, Semarang yang dipimpin oleh Bapak Waskito. Grup musik ini merupakan sebuah grup musik bergenre dangdut yang mengedepankan kualitas bermusik untuk recording sehingga karya mereka dapat dinikmati oleh seluruh masyarakat Indonesia dari kaset hasil rekaman yang dilakukan. Grup ini tidak mengejar tanggapan di acara-acara kampung seperti grup-grup musik dangdut lainnya, karena biaya penyewaan grup musik Rhomantika yang ternilai mahal karena mencapai $\mathrm{Rp}$ 50.000.000,00. Hal itu disebabkan oleh konsep grup musik Rhomantika yang tampil dengan tata suara, tata lighting dan tata panggung milik pribadi, sehingga banyak masyarakat yang keberatan untuk mendatangkan grup musik ini. Rutinitas yang dilakukan oleh grup musik Rhomantika adalah merekam ulang lagu-lagu dangdut klasik dengan beberapa aransemen dan bentuk penyajian yang berbeda. Selain itu, dalam merekam ulang lagu-lagu dangdut klasik tersebut, Bapak Waskito mengundang langsung beberapa penyanyi dangdut ibu kota penyanyi asli lagu dangdut klasik yang akan direkam. Seperti: Rita Sugiarto, Ikke Nurjanah, Caca Handika, Mansyur S. dan masih banyak penyanyi lain yang tergabung dan mengikuti proses rekaman bersama grup musik Rhomantika.

Grup musik Rhomantika tampil di panggung indoor dan juga outdoor. Pada panggung indoor grup musik ini menampilkan hasil recording sekaligus dilaksanakan kegiatan shooting video clip bersama seluruh pemain grup Rhomantika dan penyanyi ibu kota, sedangkan pada panggung outdoor grup ini ditampilkan pada acara besar.

Tujuan utama dibentuknya grup ini adalah untuk melestarikan musik dangdut klasik di Indonesia yang mulai tenggelam karena banyaknya lagu-lagu dangdut baru yang mengedepankan musik dangdut house, sehingga dengan adanya rekaman ulang ini dimaksudkan agar masyarakat teringat kembali dengan lagu-lagu dangdut klasik yang terdahulu dengan beberapa aransemen untuk menambahkan kesan indah dan menarik pada lagu tersebut.

Alasan peneliti memilih bentuk penyajian yang ada pada grup musik Rhomantika adalah keunikan model penyajian musik dangdut yang dibedakan menjadi dua, yaitu model penyajian pada panggung indoor dan panggung outdoor yang tentunya tidak 
lepas dari kosep penyajian yang meliputi tata rias, tata busana, tata panggung, tata lampu, tata suara, tata urutan pmentasan dan aransemen musik seperti nada, irama, lagu, tempo, dinamika, harmoni dan ekspresi. Selain itu, grup musik Rhomantika lebih mementingkan kualitas penampilan dengan menampilkan langsung penyanyi ibu kota baik dalam acara panggung indoor maupun panggung outdoor. Peneliti memilih model kemasan penyajian musik dangdut Grup Rhomantika, Mijen, Semarang karena belum ada yang melakukan penelitian mengenai seluk beluk bentuk penyajian dan aransemen yang ada pada musik dangdut klasik sebelumnya. Selain itu, peneliti ingin memperkenalkan bentuk penyajian dan aransemen musik dangdut klasik sebagai musik asli Indonesia kepada para pembaca, khusunya pemuda yang untuk saat ini hanya mengenal perkembangan musik dangdut dalam bentuk musik dangdut koplo dan musik dangdut house.

\section{METODE}

Pendekatan yang digunakan dalam penelitian ini adalah deskriptif kualitatif. Deskriptif adalah penguraian tentang kejadian-kejadian berdasarkan data-data baik yang tertulis maupun tidak tertulis. Data yang diperoleh (berupa kata-kata, gambar, perilaku) tidak dituangkan dalam bilangan atau angka, melainkan tetap dalam bentuk kualitatif yang memiliki arti lebih kaya dari sekedar angka atau frekuensi (Margono, 2005 : 39). Menurut (Bog dan dan Taylor dalam Sumaryanto, 2002:2), penelitian kualitatif adalah prosedur penelitian yang menghasilkan data deskriptif berupa kata-kata tertulis atau lisan dari orangorang dan perilaku yang dapat diamati. Metode penelitian kualitatif adalah metode penelitian yang berlandaskan pada filsafat postpositivisme, digunakan untuk meneliti pada kondisi obyek yang alamiah, (sebagai lawannya adalah eksperimen) dimana peneliti adalah sebagai instrumen kunci, teknik pengumpulan data dilakukan secara triangulasi (gabungan), analisis data bersifat induktif atau kualitatif, dan hasil penelitian kualitatif lebih menekankan makna dari pada generalisasi (Sugiyono, 2011:9).

Jenis pendekatan dalam penelitian bentuk penyajian musik dangdut klasik pada Grup Rhomantika, Mijen, Semarang ini dikategorikan sebagai penelitian kualitatif, yaitu tradisi tertentu dalam ilmu pengetahuan sosial yang secara fundamental bergantung pada pengamatan terhadap manusia dalam kawasannya sendiri dan berhubungan dengan orang-orang tersebut dalam bahasanya dan dalam peristiwanya (Moeloeng dalam Margono, 2005 :36).

Teknik pengumpulan data yang digunakan peneliti diantaranya yaitu, studi pustaka, observasi, wawancara, dan studi dokumen. Pengertian teknik pengumpulan data menurut Arikunto (2002:134) adalah caracara yang dapat digunakan oleh peneliti untuk mengumpulkan mengumpulkan data, di mana cara tersebut menunjukan pada suatu yang abstrak, tidak dapat diwujudkan dalam benda yang kasat mata, tetapi dapat dipertontonkan penggunaannya. Dalam hal pengumpulan data ini, penulis terjun langsung pada objek penelitian untuk mendapatkan data yang valid, maka peneliti menggunakan metode sebagai: (1) Observasi, (2) Wawancara, dan (3) Dokumentasi.

. Menurut Bogdan dan Taylor (dalam Sumaryanto, 2002:17), pengamatan atau observasi dapat diklasifikasikan atau pengamatan melalui cara berperan serta dan tidak berperan serta. Pengamatan menurut Moleong (dalam Sumaryanto, 2002:17) dapat pula dibagi ke dalam pengamatan terbuka dan pengamatan tertutup. Pengamatan terbuka diketahui oleh subjek sehingga subjek dengan sukarela memberikan kesempatan kepada pengamat untuk mengamati peristiwa yang terjadi dan mereka menyadari bahwa ada orang lain yang sedang mengamati mereka. Sebaliknya pada pengamatan tertutup, pengamat melakukan penelitian tanpa diketahui oleh para subjeknya. Untuk menjaring berbagai informasi yang terkait dengan berbagai permasalahan yang telah ditentukan, dilakukan observasi terbuka baik secara langsung maupun sumber lisan.

Adapun jenis observasi yang penulis gunakan dalalm penelitian ini berupa observasi tidak berperan serta (non participant observation), dimana penulis tidak turut aktif dalam kegiatan yang dijalankan oleh para subjek, tetapi penulis cukup melakukan pengamatan saja. Observasi ini akan peneliti lakukan dengan ke lokasi penelitian yaitu di 
Mijen, Kota Semarang. Melalui observasi, data yang akan diperoleh antara lain; gambaran umum bentuk penyajian musik dangdut klasik grup Rhomantika di Mijen, Semarang dari 2 model yaitu kemasan indoor dan outdoor dilengkapi dengan konsep bentuk penyajian dan bentuk aransemen.

Wawancara adalah percakapan dengan maksud tertentu yang dilakukan oleh dua pihak, yaitu pewawancara (interviewer) yang mengajukan pertanyaan dan yang diwawancarakan (interviewee) yang memberikan jawaban atas pertanyaan (Moleong, 2000:138). Menurut Usman, wawancara ialah Tanya jawab lisan antara dua orang atau lebih secara langsung (1996:57-58).

Menurut Patton (1980:197) wawancara dibagi sebagai berikut : (a) wawancara pembicaraan informal, (b) pendekatan menggunakan petunjuk umum wawancara, (c) wawancara baku terbuka. Jenis wawancara pembicaraan informal, pertanyaan yang diajukan sangat bergantung pada spontanitas pewawancara dalam mengajukan pertanyaan pada responden. Sedangkan pendekatan menggunakan petunjuk umum wawancara mengharuskan pewawancara membuat kerangka garis besar pokok-pokok yang dirumuskan tidak perlu ditanyakan secara berurutan. Petunjuk wawancara hanyalah berisi petunjuk secara garis besar tentang proses dan isi wawancara untuk menjaga agar pokok-pokok yang direncakan dapat seluruhnya tercakup. Wawancara baku terbuka adalah wawancara yang menggunakan seperangkat pertanyaan baku. Urutan pertanyaan, kata-kata yang digunakan serta cara penyajian sama untuk semua responden.

Pembagian unsur wawancara dikemukakan pula oleh Guba dan Lincoln (1981:160-170) yaitu (a) wawancara oleh tim atau panel, (b) wawancara tertutup dan terbuka, (c) wawancara riwayat secara lisan, dan (d) wawancara terstruktur dan tak terstruktur. Wawancara oleh tim berarti wawancara dilakukan tidak hanya oleh satu orang, tetapi oleh dua orang atau lebih terhadap seseorang yang diwawancarai. Wawancara tertutup biasanya responden tidak mengetahui bahwa mereka sedang diwawancara. Cara demikian tidak tepat jika digunakan dalam penelitian kulatiatif yang biasanya berpandangan terbuka. Jadi, dalam penelitian kualitatif sebaiknya digunakan wawancara terbuka yang para subjeknya tahu bahwa mereka sedang diwawancarai dan dapat mengetahui pula apa maksud dan tujuan wawancara itu. Sedangkan wawancara riwayat secara lisan adalah wawancara terhadap orangorang yang pernah membuat sejarah atau membuat karya ilmiah besar, social, pembangunan, perdamaian dan sebagainya. Maksud wawancara semacam ini adalah untuk mengungkapkan riwayat hidup, pekerjaan, ketekunan, kesenangannya dan lain-lain. Wawancara terstruktur adalah wawancara yang pewawancaranya menetapkan sendiri masalah dan pertanyaan yang akan diajukan dengan tujuan untuk mencari jawaban terhadap hipotesa kerja. Wawancara tak terstruktur adalah wawancara yang digunakan untuk menemukan hasil informasi yang bukan baku atau informasi tunggal.

Dengan uraian jenis wawancara tersebut, peneliti menggunakan jenis wawancara terbuka dan wawancara terstruktur. Tujuan menggunakan wawancara terbuka adalah agar responden mengetahui bahwa sedang diwawancara dan memahami maksud dan tujuan dilakukan wawancara, sehingga responden dapat memberikan informasi yang sesuai dengan kebutuhan peneliti.

Sebelum diadakan wawancara peneliti terlebih dahulu menyiapkan beberapa pertanyaan agar pelaksanaannya dapat terarah sesuai dengan tujuan yang hendak dicapai. Metode wawancara digunakan karena jika hanya dengan menggunakan metode observasi saja belum cukup sehingga perlu adanya teknik lain untuk melengkapinya. Melalui wawancara akan diperoleh data yang lebih spesifik dan akurat atau khusus sesuai dengan tujuan penelitian. Dalam melakukan wawancara peneliti menggunakan pedoman wawancara untuk memperoleh data dari responden. Untuk memperoleh data yang diperlukan, penulis akan mewawancarai berbagai pihak yang akan memberi informasiinformasi berkaitan dengan penelitian ini. Pihak-pihak yang akan diwawancarai adalah pengelola, para penyaji, vokalis, backing vocal, penata artistik baik dari tata rias, tata lampu, tata busana, tata suara maupun tata panggung.

Dilihat dari sumber data, bahan tambahan yang berasal dari sumber tertulis 
dapat dibagi atas sumber yang berasal dari buku atau majalah ilmiah, arsip, dokumen pribadi, dan dokumen resmi (Sumaryanto, 2007:100). Dokumen merupakan catatan peristiwa yang sudah berlalu. Teknik studi dokumen adalah teknik pengumpulan data yang berhubungan dengan dokumen, baik dalam bentuk laporan, statistik, surat-surat resmi, maupun catatan harian dan semacamnya baik yang diterbitkan, maupun yang tidak diterbitkan (Ali, 1985:41). Dokumen bias berbentuk tulisan, gambar, atau karyakarya momumental dari seseorang, bias berbentuk catatan harian, foto, gambar, dan sejarah kehidupan (Sugiyono, 2008:240). Dalam hal ini, studi dokumen dilakukan dengan mengumpulkan data seperti; dokumen foto, surat kabar, serta data-data lain berkaitan dengan bentuk penyajian musik dangdut klasik pada grup musik Rhomantika, Mijen, Semarang. Hasil dari dokumen-dokumen tersebut selanjutnya di organisasi sedemikian rupa hingga menjadi data yang membantu melengkapi hasil observasi dan wawancara.

\section{HASIL DAN PEMBAHASAN}

Penelitian dilakukan selama satu bulan, pengumpulan data diperoleh dengan observasi yang dilakukan pada bulan Februari 2017. Kemudian dilanjutkan dokumentasi dan wawancara pada bulan maret sampai April tahun 2017. Objek penelitian adalah grup music Rhomantika, Mijen, Semarang. Pengumpulan data pada penelitian ini diperoleh menggunakan instrumen dan pedoman baik observasi, wawancara maupun dokumentasi.

Grup Musik Rhomantika merupakan sebuah grup musik dangdut klasik yang berada di Jalan Wonolopo Raya, RT 02, RW o7, Kecamatan Mijen, Kota Semarang didirikan pada bulan September tahun 2014 dibawah pimpinan Bapak Waskito. Nama Rhomantika dipilih atas izin dan rekomendasi dari Rhoma Irama yang diambil dari salah satu judul lagu dangdut klasik milik beliau yang berjudul "Rhomantika". Pemilihan nama "Rhomantika" tersebut memiliki arti warna sari kehidupan. Diharapkan dengan adanya musik dangdut klasik yang memberikan sajian nada dan lirik yang berisi kehidupan sehari-hari akan menjadi sebuah gambaran bagi para pendengar musik dangdut klasik, untuk dapat mewakili berbagai macam warna kehidupan seperti senang, sedih, miskin, kaya, sehat, duka dan lara.

Dalam wawancara bersama Bapak Waskito (pendiri grup Musik Rhomantika) yang berusia 45 tahun, awal berdirinya grup musik Rhomantika adalah adanya keinginan beliau untuk membuat grup musik dangdut yang dalam penyajiannya hanya memainkan lagu-lagu yang bernuansa dangdut klasik. Keinginan tersebut semakin kuat dengan adanya sebuah niat untuk melestarikan musik dangdut klasik sebagai musik original Indonesia. Dalam mendirikan sebuah grup musik perlu adanya pemain dan penyanyi, sehingga beliau melakukan perekrutan anggota dengan mengadakan audisi pada bulan September tahun 2013. Kemudian beliau mengumpulkan beberapa musisi serta penyanyi yang berkompeten dalam musik dangdut klasik untuk mengikuti audisi. Audisi ini dilakukan untuk dapat menyeleksi pemain musik dan penyanyi yang tidak hanya berkompeten dalam musik dangdut klasik, namun mencari keselarasan dan harmonisasi grup agar terjalin ikatan emosional antar pemain dan ada rasa saling memiliki sebagai sebuah tim. Dalam jangka waktu setahun grup ini tidak memiliki nama dengan alasan agar musisi yang tereliminasi tidak dapat mengklaim dirinya sebagai jebolan grup musik ini.

Pada September 2013 hingga September 2014, grup musik ini belum ditampilkan di luar studio, karena menurut pendiri belum layak ditampilkan jika kemampuan dan teknik para anggota grup tidak diasah terlebih dahulu. Maka kegiatan mereka dalam jangka waktu setahun sebelum grup Rhomantika diresmikan adalah berlatih dan mengasah teknik permainan musik dangdut klasik yang diasuh langsung oleh pendiri, Bapak Waskito. Pada tahun 2014 grup musik Rhomantika resmi didirikan dengan jumlah 18 personil yang terdiri dari 4 pemain alat musik tiup yaitu 1 pemain trombone, 1 pemain trumpet, 1 pemain saxophone tenor dan 1 pemain saxophone alto. Terdapat 4 backing vocal, 1 pemain bass, 1 pemain kendang, 1 pemain drum,1 pemain tamborin,1 pemain mandolin, 1 pemain gitar rhythm, 1 pemain gitar melodi, 1 pemain suling dan 2 
pemain keyboard sebagai melodi string dan pengiring.

Grup Musik Rhomantika mempunyai tujuan untuk melestarikan musik dangdut klasik sebagai musik original Indonesia. Dengan adanya grup musik Rhomantika, pendiri berharap agar musik dangdut klasik tetap dilestarikan serta dapat dikenal oleh generai-generasi yang baru. Karena pada kenyataannya, jenis lagu dangdut yang dimainkan oleh grup musik lain adalah jenis dangdut klasik hanya saja iramanya sengaja disajikan dalam bentuk musik koplo. Hal inilah yang menjadi kekhawatiran, apabila tidak dilestarikan maka masyarakat akan menilai bahwa lagu yang dimainkan dengan nuansa musik koplo itu adalah lagu yang asli. Untuk menghindari penilaian tersebut maka Bapak Waskito mendirikan grup musik Rhomantika yang dalam penyajiannya hanya memainkan lagu-lagu dangdut klasik untuk dapat dilestarikan sebagai musik asli Indonesia.

Kegiatan yang dilakukan selama kurun waktu 3 tahun sejak September 2014 adalah melakukan rekaman, tampil pada beberapa even dan kegiatan "Festival Penyanyi Dangdut”.Kegiatan tersebut dilakukan dibeberapa tempat, baik indoor maupun outdoor. Kegiatan rekaman dilakukan bersama penyanyi dangdut klasik ibu kota seperti Rita Sugiarto, Caca Handika, Mansyur S., Inne Cyntia, Evi Tamala, Yus Yunus, Lilin Herlina, Ikke Nurjanah serta beberapa penyanyi lokal. Semua kegiatan rekaman dilakukan di Studio Rhomantika baik dalam musik record, take vocal maupun shooting video klip. Musik record dilakukan satu bulan sebelum shooting video klip dilaksanakan, sedangkan take vocal dilakukan 2 hari sebelum shooting video klip. Berikut jadwal shooting video klip,

\begin{tabular}{|c|l|l|l|}
\hline No & \multicolumn{1}{c|}{ Waktu } & \multicolumn{1}{c|}{ Nama } & Judul Lagu \\
\hline 1. & $\begin{array}{l}\text { Jumat, } 13 \\
\text { Februari 2015 }\end{array}$ & $\begin{array}{l}\text { Inne } \\
\text { Cyntia }\end{array}$ & Selalu Rindu \\
& & Bukan yang \\
& & & Pertama \\
& & & Perpisahan \\
\hline
\end{tabular}

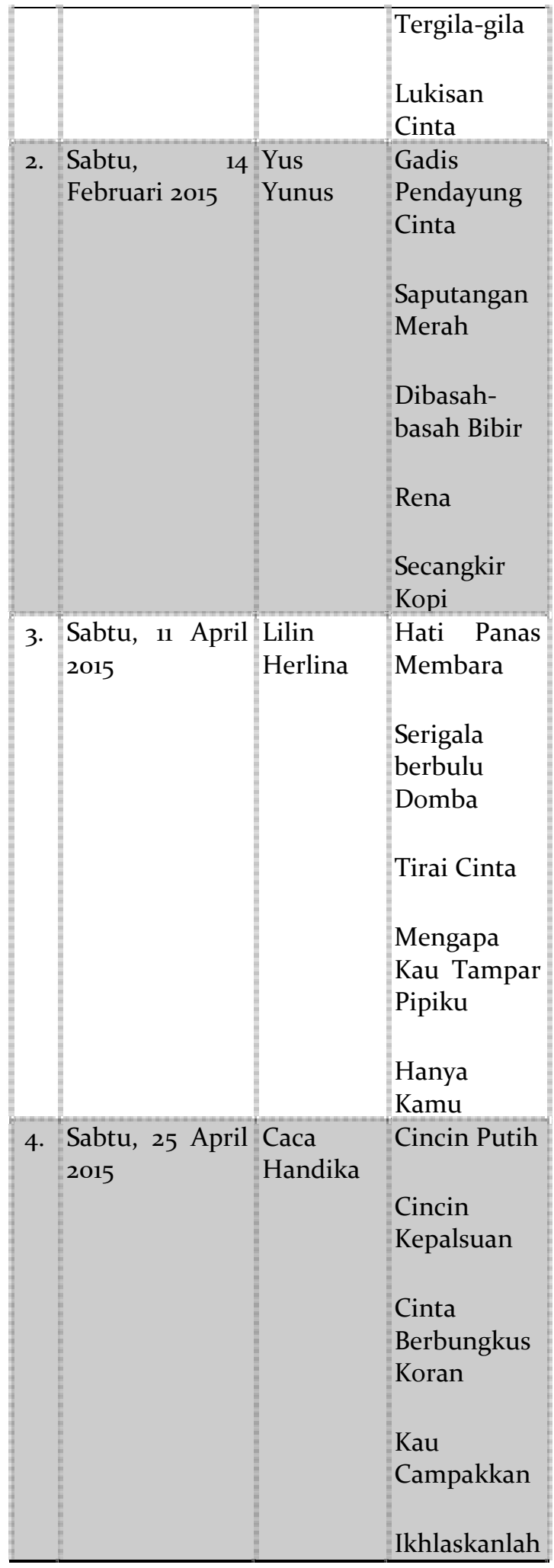

Kegiatan rekaman dilakukan guna mengasah kemampuan bermusik para musisi agar teknik permainan musik dangdut klasik yang dimiliki lebih berkompeten. Selain itu rekaman ini digunakan sebagai sarana untuk 
mempromosikan grup musik Rhomantika pada masyarakat. Hasil rekaman dicetak sebanyak 2000 keping untuk disebarkan ke seluruh wilayah di Indonesia.

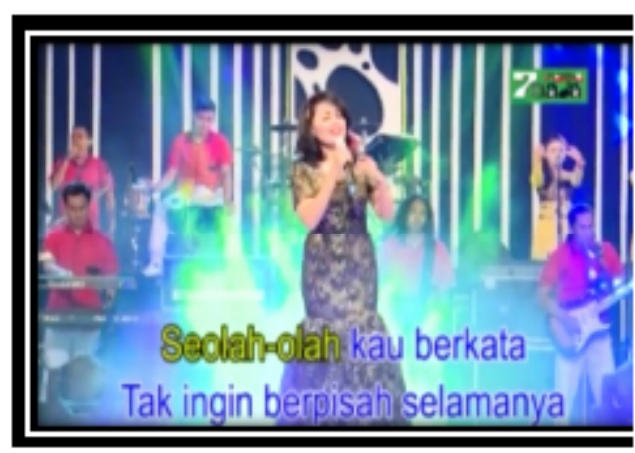

Foto 4.2. : Hasil Shooling Video Klip Bersana Rita Sugiarto

Kegiatan lain yang dilakukan adalah tampil pada beberapa even besar seperti kegiatan tahun baru, kegiatan pesta durian dan beberapa acara hajatan. Even tahun baru dilaksanakan pada 31 Desember 2016 di lapangan Jatisari, Kecamatan Mijen. Pada even tahun baru, grup Musik Rhomantika dimeriahkan oleh Elvy Zubaidah, Caca Handika dan Rita Sugiarto dan beberapa penari latar. Even tahun baru ini dilakukan dari pukul 19.30-0o.oo memasuki tanggal o1 Januari 2017. Even Pesta Durian dilaksanakan pada 9 November 2014 di halaman ruko Jatisari, Kecamatan Mijen yang dimeriahkan oleh penyanyi-penyanyi dangdut lokal Jawa Tengah. Even Pesta Durian dilaksanakan dari pukul 13.00-16.oo. Grup Musik Rhomantika juga pernah menghadiri hajatan pada berbagai daerah, seperti DKI Jakarta, Kota Semarang, Kabupaten Batang, Kabupaten Cilacap, dan Kabupaten Kendal.

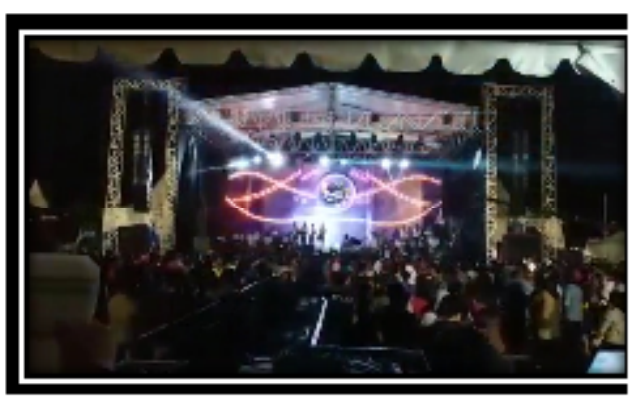

Foto 4.3. : Grup khomantika dalam Event Pesta Durian

Pemain dalam grup Musik Rhomantika, terdiri dari Pemain Suling, Pemain Gitar Rhythm, Pemain Gitar Melodi,
Pemain Kendang, Pemain Tamborin, Pemain Drum elektrik, Pemain Keyboard String, Pemain Keyboard Rhythm, Pemain Mandolin, Pemain Gitar Bass, Pemain Saxophne Tenor, Femain Saxophone Alto, Pemain Trombone, Pemain Trumpet dan Backing Vocal. Biasanya yang memimpin dan mengatur jalannya pementasan dangdut klasik oleh grup Musik Rhomantika, mulai dari mengatur persiapan dan perlengkapan pementasan dari mulai pra pementasan sampai pementasan adalah penanggung jawab pemain, yaitu pemain musik drum elektrik.

Tata suara pada pertunjukan musik dangdut klasik oleh grup Musik Rhomantika sangat berkualitas karena difasilitasi dengan alat tata suara yang baik. Semua alat tata suara yang digunakan sangat menunjang penampilan grup Musik Rhomantika. Adapun alat tata suara yang digunakan adalah Mixer Monitor : Sound Craft 40 channel, Mixer FOH : SSL 40 channel, Speaker : JBL Vertech 12 inch dan 18 inch, Twiter 1 inch N 8o, Floor Monitor : RCF ART 74515 inch, RCF 5030 A two way 15 inch, RCF 18 inch, Amplifier : Marshall JCM 900 (Gitar Melodi), Roland Jazz Corus 120 (Mandolin dan Gitar Rhythm), GK RB 7000 (Bass), PV KB 300 (Keyboard), Management Speaker : Drive Rack 26o, Mic : Sennheizer, Shure SM 58, Shure SM 57.

Tidak hanya alat tata suara yang baik, namun dengan adanya penata suara yang berkompeten mampu menghasilkan suara yang baik saat pertunjukan dilakukan. Menurut Sucipno (soundman), model kemasan bentuk penyajian baik indoor maupun outdoor pada bagian tata suara hampir sama, yaitu menyeimbangkan suara baik dari instrumen maupun vokal dengan cara membagi suara sesuai karakter yang dihasilkan. Semua alat musik yang mempunyai karakter low ( mempunyai frekuensi 45-125 Hz ) seperti drum, bass dan kendang dut diatur masuk ke speaker JBL 18" (bagian bawah). Semua alat musik yang mempunyai karakter middle ( mempunyai frekuensi 125-3.000 $\mathrm{Hz}$ ) seperti suling, keyboard, brass, snare drum, backing vokal dan vokal utama diatur masuk ke speaker JBL 12" (bagian atas). Semua alat musik yang mempunyai karakter high ( mempunyai 
frekuensi 3.000-10.00o Hz ) seperti mandolin, gitar rhythm, simbal, tamborin diatur masuk ke twiter. Hal yang membedakan bentuk tata suara pada model kemasan bentuk penyajian baik indoor maupun outdoor adalah pada susunan letak speaker dan floor monitor yang memberikan hasil berbeda.

Kesulitan dalam mengatur tata suara pada grup musik Rhomantika adalah mencari clarity tiap instrumen agar terdengar detail suara dan karakter tiap alat musiknya. Selain itu kesulitan terjadi pada lokasi pertunjukan yang berbentuk indoor sehingga suara yang dihasilkan menggema dan memantul dan sering terjadi feedback. Terutama pada vokal utama. Cara mengatasinya adalah dengan mengatur volume monitor $\mathrm{FOH}$ dikurangi dari odb ke $-3 \mathrm{db}$.

Waktu pertunjukan grup musik Rhomantika mempunyai perbedaan pada model kemasan bentuk penyajian baik indoor maupun outdoor. Pada model kemasan indoor, kegiatan dilakukan dari pagi hingga malam berkisar antara 12-15 jam. Hal itu disebabkan oleh adanya kegiatan shooting video klip yang dilakukan secara berulang-ulang dengan konsep dan urutan lagu yang berbeda-beda. Banyak kemungkinan dilakukan retake atau pengambilan gambar kembali karena hasil sebelumnya dinilai kurang memuaskan. Pada model kemasan outdoor, penampilan dilakukan berkisar antara 3-4 jam dengan waktu yang telah disesuaikan dengan kehendak yang punya hajat. Pada pagi hari pertujukan dilakukan berkisar pukul o9.oo12.00, siang pukul 13.00-16.0o ataupun malam pukul 19.30-23.30, baik itu masyarakat umum maupun pemerintah.

Tata panggung yang digunakan dalam pementasan musik dangdut klasik oleh grup Musik Rhomantika ada dua jenis, yaitu panggung indoor dan panggung outdoor. Panggung indoor berada di dalam studio Rhomantika, sedangkan panggung outdoor berada di tempat pelaksanaan pementasan grup Musik Rhomantika sesuai dengan keinginan panitia pelaksana. Dalam tata panggung, baik indoor maupun outdoor terdapat 3 bagian panggung yaitu, lidah panggung bagian depan, panggung utama bagian tengah dan panggung tambahan bagian belakang. Lidah panggung berukuran 6 x $6 \mathrm{~m}$ digunakan untuk vokal utama agar interaksi dengan penonton lebih mudah. Panggung utama bagian tengah berukuran $9 \times 6 \mathrm{~m}$ digunakan untuk personil grup musik Rhomantika yang memainkan instrumen suling, keyboard string, keyboard rhythm, gitar melodi, gitar rhythm, mandolin, gitar bass dan tamborin. Pada panggung tambahan bagian belakang berukuran 9 x 4 mdigunakan untuk instrumen kendang, drum elektrik, saxophone alto, saxophone tenor, trombone, trumpet dan backing vokal. Panggung menggunakan landasan atau dasar stage yang rata dan tidak bergoyang/mantap. Hal ini merupakan syarat mutlak karena bila panggung dalam keadaan tidak rata dikhawatirkan personil akan mengalami kesulitan ketika akan tampil, terutama stage untuk backing vokal

Tata rias model kemasan bentuk penyajian baik indoor maupun outdoor tidak ada perbedaan. Tata rias yang digunakan para personil grup Musik Rhomantika dibedakan menjadi dua, tata rias wanita dan tata rias pria. Tata rias wanitaadalah vintage dan smooky style. Vintage adalah jenis tata rias seperti era tahun 8o-an dengan karakteristik lipstik tebal dan rambut bersanggul. Sedangkan smooky style adalah jenis tata rias yang lebih menonjolkan bagian mata dan alis yang tebal. Pada penataan rambut banyak bermain dengan alat pengriting rambut dan hairspray serta pewarnaan rambut sesuai kebutuhan penyanyi. Tata rias pria terkesan simpel dan natural, hanya bermain pada warna coklat muda dan coklat tua, pada warna shading hanya menggunakan warna coklat tua agar terkesan lebih fresh dan tidak pucat. Pada bentuk rambut biasa menggunakan gel agar tambak lebih segar.

Tata busana model kemasan bentuk penyajian baik indoor maupun outdoor tidak ada perbedaan. Tata busana grup music Rhomantika dibedakan menjadi dua, tata busana wanita dan tata busana pria. Tata busana yang dikenakan para pemain grup Musik Rhomantika, Mijen, Semarang adalah memakai kostum milik grup Musik Rhomantika baik bagi wanita maupun pria yang sudah dipersiapkan. Pada tata busana penyanyi dan backing vokal wanita menggunakan gaun pesta dengan bahan tile prancis, satin bridal, bordir dan payet jepang 
agar lebih terkesan glamour. Pemilihan gaun untuk musik dangdut klasik cenderung panjang, kain berkilau, terkesan mewah pada bagian atas dengan adanya payet dan manikmanik sesuai dengan karakter penyanyi. Penampilan penyanyi dan backing vokal terlihat lebih lengkap dengan tambahan aksesoris headpiece (hiasan yang digunakan pada bagian kepala, baik untuk wanita berhijab maupun tidak berhijab) dan obi (sabuk dibagian perut atau pinggang) serta penggunaan sepatu ber hak tinggi agar terlihat lebih cantik. Pada tata busana personil pria menggunakan kemeja, celana dan sepatu pantovel ditambah dengan aksesoris dasi dan slayer sesuai karakter pemain.

Tata lampu model kemasan bentuk penyajian baik indoor maupun outdoor tidak ada perbedaan. Tata lampu pada grup Musik Rhomantika menggunakan beberapa buah lampu yang telah dipasang di panggung agar setiap penampilan baik pemain maupun penyanyi dapat terlihat dengan jelas. Permainan tata lampu disesuaikan dengan lagu yang sedang ditampilkan. Semua alat tata lampu yang digunakan sangat menunjang penampilan grup Musik Rhomantika. Adapun alat tata lampu yang digunakan adalah Mixer Avolites Pearl Tiger, DMX Disco 250, Lampu 10 moving head beam 230, 18 par led, 10 par can 64, 4 freshnel. Kesulitan dalam mengatur tata lampu pada grup musik Rhomantika adalah menyesuaikan lampu dengan konsep lagu yang ditampilkan, sehingga pada bagian tata lampu harus memahami dan maksud lagu terlebih dahulu agar isi dan konsep lagu dapat tersampaikan dengan baik oleh penonton.

Sajian dalam pementasan musik dangdut klasik oleh grup musik Rhomantika memiliki beberapa bagian pementasan mulai dari bagian awal pertunjukan, bagian inti pertunjukan dan bagian akhir pertunjukan baik pada panggung indoor maupun outdoor. Bagian awal pada panggung indoor bagian awal kegiatan yang dilakukan adalah recording instrumen satu persatu. Diawali dengan record instrumen gitar rhythm dan keyboard rhythm, diikuti dengan alat musik perkusi dalam hal ini adalah kendang tak dan dut, tamborin dan drum. Setelah itu kegiatan record dilanjutkan dengan instrumen melodi dan pengisi atau filler seperti trombone, saxophone alto, gitar melodi, mandolin, bass, saxophone tenor, trumpet dan suara backing vocal. Setelah semua instrumen sudah melakukan recording, penata suara melakukan mixing agar hasil rekaman terdengar balance. Kemudian pemilik grup music Rhomantika melakukan negosiasi dengan penyanyi ibu kota untuk melakukan take vocal. Setelah waktu ditentukan, penyanyi tersebut menuju ke studio Rhomantika untuk melakukan take vocal sesuai dengan lagu-lagu yang telah ditentukan sebelumnya.

Pada panggung outdoor bagian awal pertunjukan musik dangdut klasik oleh grup musik Rhomantika, yang pertama dilakukan adalah memanjatkan do'a secara bersamasama antara owner, musisi serta penyanyi untuk kesuksesan dan kelancaran pementasan yang dipimpin pendiri grup Musik Rhomantika, Bapak Waskito.Setelah melakukan do'a bersama para musisi langsung memegang alat Musik masing masing yang akan dimainkan dan memasuki arena pementasan. Sebagai awal pertunjukan grup musik Rhomantika memainkan sebuah musik dangdut klasik tanpa menyanyikan lagu yang biasa disebut dengan instrumenal. Bagian ini digunakan oleh soundman untuk memastikan kembali keseimbangan suara yang dihasilkan antar instrumen.

Bagian inti pertunjukan pada penyajian indoor, bagian inti pertunjukan musik dangdut klasik oleh Grup Musik Rhomantika dilaksanakan di studio Rhomantika. Seluruh pemain baik instrumen maupun backing vocal dikumpulkan untuk melakukan cek sound sembari menunggu penyanyi ibu kota selesai dalam melakukan persiapan sebelum shooting video klip dimulai. Pada kegiatan shooting video klip pemain dan penyanyi hanya melakukan gerakan dengan penuh ekspresi tanpa memainkan secara langsung alat music tersebut. Hal itu juga dilakukan oleh penyanyi ibu kota dengan hanya membuka mulut dan berekspresi tanpa mengeluarkan suara indah disesuaikan dengan lagu pada rekaman yang telah dilakukan sebelumnya. Shooting video klip dilakukan sebanyak $2 x$ pengulangan. Pada bagian awal, shooting dilakukan dengan hanya menggunakan kamera depan, setelah satu lagu selesai dilanjutkan dengan menggunakan kamera tangan yang langsung menjurus pada setiap pemain pada grup music Rhomantika. 
Pada pertunjukan penyajian outdoor, bagian inti pertunjukan musik dangdut klasik oleh Grup Musik Rhomantika adalah memainkan lagu-lagu dangdut klasik yang telah dikonsep sebelumnya (pada saat latihan). Urutan lagu dangdut klasik yang ditampilkan sesuai dengan urutan yang telah dikonsep pada saat latihan. Lagu dangdut klasik yang dimainkan berkisar antara 10-15 lagu. Penyanyi menyanyikan lagu dangdut klasik secara bergantian dengan ketentuan maksimal satu penyanyi membawakan 3 buah lagu. Seluruh personil baik pemusik maupun backing vokal melakukan pertunjukan dengan berdiri kecuali pemain drum dan kendang. Sebelum penyanyi membawakan lagu dangdut klasik, terlebih dahulu MC memperkenalkan satu persatu penyanyi yang akan tampil bersama grup Musik Rhomantika. Ketika MC menyebut nama penyanyi, maka biduan akan menuju panggung untuk membawakan lagu sesuai konsep. Setelah selesai bernyanyi, MC mulai mencairkan suasana dengan sedikit gurauan dan interaksi dengan penonton kemudian memanggil nama penyanyi selanjutnya.

Pada bagian akhir pementasan musik dangdut klasik oleh grup Musik Rhomantika, baik dalam kegiatan indoor maupun outdoor adalah seluruh penyanyi menuju panggung utama bersama dengan owner grup Musik Rhomantika untuk menyanyikan lagu yang berjudul "Insya Allah". Disela-sela pertunjukan lagu tersebut owner grup Musik Rhomantika menyampaikan terimakasih serta berpamitan bahwa pertunjukan telah selesai. Dengan berakhirnya lagu "Insya Allah" maka berakhir pula pertunjukan musik dangdut klasik oleh grup Musik Rhomantika. Perbedaan pada bagian akhir pertunjukan dalam model kemasan indoor hanya pada penyampaian launching album dan harga CD tiap keping.

\section{SIMPULAN}

Penyajian musik dangdut klasik pada grup Musik Rhomantika memberikan ketertarikan dan pilihan musik dangdut di mata masyarakat kecamatan Mijen, Semarang. Dengan banyaknya grup musik dangdut yang mulai terpengaruh dengan irama musik lain, grup musik Rhomantika tetap mengusung musik dangdut klasik dengan tujuan untuk melestarikan dan memperkenalkan kepada pemuda mengenai musik asli Indonesia.
Model kemasan musik dangdut klasik terdiri dari dua aspek yaitu indoor dan outdoor. Pada model kemasan indoor, dilakukan di dalam ruangan yaitu di studio Rhomantika. Kegiatan yang dilakukan adalah melakukan video shooting bersama seluruh personil dan penyanyi ibukota dilengkapi dengan aspek penyajian yang meliputi tata suara, tata lampu, tata panggung, tata rias, tata busana yang sesuai dengan model kemasan indoor. Pada model kemasan outdoor, dilakukan di dalam ruangan yaitu di studio Rhomantika. Kegiatan yang dilakukan adalah menampilkan lagu sesuai konsep bersama penyanyi ibukota dilengkapi dengan aspek penyajian yang meliputi tata suara, tata lampu, tata panggung, tata rias, tata busana yang sesuai dengan model kemasan outdoor.

Musik dangdut klasik terdiri dari dua aspek yaitu, meliputi aspek komposisi musik dan aspek penyajian. Aspek komposisi musik dangdut klasik pada grup musik Rhomantika terdiri dari ritme, melodi, harmoni, tempo, tangganada dan ekspresi. Ritme musik dangdut klasik pada grup musik Rhomantika mempunyai beberapa pola yaitu pada tempo cepat ada 2 pola, tempo sedang 4 pola dan tempo cepat 4 pola. Melodi dangdut klasik pada grup musik Rhomantika lebih rumit karena mengedepankan cengkok dangdut klasik serta permainan yang penuh improvisasi. Harmoni dangdut klasik pada grup musik Rhomantika dominan dimainkan oleh instrumen tiup yang teridri dari saxophone tenor, saxophone alto, trumpet dan trombone serta harmonisasi suara sopran, mesosopran dan alto oleh backing vocal. Tempo dangdut klasik pada grup musik Rhomantika terdiri dari tiga macam yaitu tempo lambat, tempo sedang dan tempo cepat. Tangganada dangdut klasik pada grup musik Rhomantika menggunakan tangga nada diatonic mayor dan minor.

Pada aspek penyajian terdiri dari urutan penyajian, instrumen, pemain, tata panggung dan waktu pertunjukan, tata rias, tata busana, tata suara, tata lampu. Urutan penyajian dangdut klasik pada grup musik Rhomantika terdiri dari 3 hal, yaitu bagian awal pertunjukan dengan memainkan instrumentalia, bagian inti pertunjukan dengan memainkan lagu-lagu dangdut klasik sesuai konsep dan bagian akhir dengan memainkan lagu "Insya Allah" dari Rhoma 
Irama. Instrumen dangdut klasik pada grup musik Rhomantika lebih komplit dengan adanya 14 alat musik. Tata panggung dangdut klasik pada grup musik Rhomantika menggunakan panggung terbuka sesuai permintaan panitia penyelenggara dan panggung tertutup yang berada di Studio Rhomantika. Waktu pertunjukan dangdut klasik pada grup musik Rhomantika adalah pagi, siang dan malam hari sesuai permintaan panitia. Tata rias dangdut klasik pada grup musik Rhomantika dibedakan antara pria dan wanita karena pria lebih simple dibandingkan wanita. Tata busana dangdut klasik pada grup musik Rhomantika wanita menggunakan gaun panjang dan sepatu hak tinggi, sedangkan pada pria menggunakan kemeja, celana, slayer dan sepatu. Tata suara dan tata lampu dangdut klasik pada grup musik Rhomantika difasilitasi dengan alat yang berkualitas dengan tujuan agar pertunjukan dapat berjalan dengan baik dan penonton dapat menangkap konsep lagu dangdut klasik yang dimainkan.

\section{UCAPAN TERIMA KASIH}

Ucapan terima kasih penulis sampaikan kepada Bapak Drs. Moh. Muttaqin,M.Hum. yang telah membimbing serta selaku ketua jurusan yang membantu mempermudah segala administrasi. Kemudian kepada Grup Musik Rhomantika, terkhusus Pak Waskito yang telah bersedia membimbing penulis dalam melakukan penelitian. Kepada orangtua dan orang terdekat yang senantiasa memberi doa restu serta dukungan yang tiada hentinya hingga skripsi ini terselesaikan. Terima kasih.

\section{DAFTAR PUSTAKA}

Banoe, Pono. 2003. Kamus Musik. Yogyakarta: Kanisius.

Semarang: IKIP Semarang Press.

Bungin, Burhan. 2011. Penelitian Kualitatif:

Komunikasi, Ekonomi,Kebijakan

Publik, dan Ilmu Sosial Lainnya.

Jakarta : Kencana.

Edmund Prier, Karl. 2009. Kamus Musik. Yogyakarta: Rejeki.

Kayam, Umar. 1981. Seni, Tradisi, Masyarakat. Jakarta: Sinar Harapan.
Koentjaraningrat. 1984. Kebudayaan Jawa. Jakarta: PN Balai Pustaka.

Masunah, J dan Nara Wati. 2003. Seni dan Pendidikan Seni (Sebuah $\mathrm{P}_{4}$ ST UPI.

Bungarampai). Bandung:

Miles \& Huberman. 2007. Analisis Data Kualitatif Terjemahan Tjetjep Rohendi

Rohidi. Jakarta: Universitas Indonesia Press.

Moleong, Lexy J. 2009. Metodologi Penelitian Kualitatif. Bandung: PT Remaja Rosdakarya.

Mugiarto, Sal. 1995. Cakrawala Pertunjukan

Budaya Mengkaji Batas-batas Arti Pertunjukan. Yogyakarta: Jurnal MSPI.

Nasution. 1988. Metode Penelitian Naturalistik Kualitatif. Bandung: Tarsito.

Patton, Michael Quinn. 1987. Qualitative Evaluation Methods. Beverly Hills: Sage Publications.

Pusat Bahasa Departemen Pendidikan Nasional. 2005. Kamus Besar Bahasa Indonesia Edisi Ketiga. Jakarta: Balai Pustaka.

Riyanto, Yatim. 1996. Metodologi Penelitian Pendidikan Suatu Tinjauan Dasar. Surabaya: SIC.

Sedyawati, Edi. 1980. Pertumbuhan Seni Pertunjukan. Jakarta: Pustaka Sinar Harapan.

Soedarsono, R.M. 2002. Seni Pertunjukan Indonesia di Era-Globalisasi. Yogyakarta: Gajah Mada University Press.

Sugiyono. 2011. Metode Penelitian Kuantitatif, Kualitatif dan RED. Bandung: Alfabeta.

Sumaryanto, Totok. 2002. Paparan Perkuliahan Mahasiswa Penelitian Pengajaran. Semarang: Sendratasik Unnes.

Susetyo, Bagus. 2007. Pengkajian Seni Pertunjukan Indonesia.Semarang: Jurusan Sendratasik Fakultas Bahasa dan Seni.

M. Muttaqin. 2006. Musik Dangdut dan Keberadannya di Masyarakat : Tinjauan dari segi Sejarah dan Perkembangannya. Harmonia: Jurnal of Arts Research and Education. Volume : 3 . No : 45-53

A Romadhon. 2013. Musik Dangdut di Grup Baladika Semarang dalam Konteks Perubahan Sosial Budaya. Catharsis : 
Journal Of Arts Education. Volume : 1.

No : $37-45$

Santoso, Aji. 2008. Bentuk Pertunjukan dan

Fungsi Sosial Musik Dangdut pada grup Musik El-Nada, Gunung Pati, Semarang.

Catharsis : Journal Of Arts Education.

Volume : 1. No : 52-59 